\title{
Periodic Behavior of Cavitation Cloud Shedding in Submerged Water Jets Issuing from a Sheathed Pipe Nozzle
}

\author{
Guoyi Peng1* , Ayaka Wakui' ${ }^{2}$, Yasuyuki Oguma ${ }^{1}$, Seiji Shimizu${ }^{1}$, Hong Ji ${ }^{3}$ \\ ${ }^{1}$ Department of Mechanical Engineering, College of Engineering, Nihon University, Koriyama, Japan \\ ${ }^{2}$ Graduate School of Engineering, Nihon University, Koriyama, Japan \\ ${ }^{3}$ College of Energy and Power Engineering, Lanzhou University of Technology, Lanzhou, China \\ Email: *peng@mech.ce.nihon-u.ac.jp
}

How to cite this paper: Peng, G., Wakui, A., Oguma, Y., Shimizu, S. and Ji, H. (2018) Periodic Behavior of Cavitation Cloud Shedding in Submerged Water Jets Issuing from a Sheathed Pipe Nozzle. Journal of Flow Control, Measurement \& Visualization, 6, 15-26.

https://doi.org/10.4236/jfcmv.2018.61002

Received: May 9, 2017

Accepted: November 2, 2017

Published: January 3, 2018

Copyright (ㅇ 2018 by authors and Scientific Research Publishing Inc. This work is licensed under the Creative Commons Attribution International License (CC BY 4.0).

http://creativecommons.org/licenses/by/4.0/

\begin{abstract}
The behavior of cavitation cloud shedding in submerged water jets issuing from a sheathed pipe nozzle is investigated experimentally by high-speed camera visualization observation. Experiments are carried out under different cavitation numbers decreased to 0.01 with increase of the injection pressure, and the frequency spectrum of cavitation cloud shedding is evaluated by statistical analysis of a sequence of high-speed camera images. Experiments demonstrate that cavitation clouds appear when the cavitation number $\sigma$ decreases to the level of $0.5-0.7$ and developed cavitation clouds shed downstream periodically at multiple frequencies. The low frequency components of cavitation cloud shedding is basically dependent upon the pressure pulsation of plunger pump, which is often employed in various industry application of water jets. However, the high frequency components are closely related to the shedding of vortexes and the collapsing of cavitation clouds, which are dependent on the flow structure of submerged jets and the property of cavitation clouds consisted of numerous bubbles.
\end{abstract}

\section{Keywords}

Water Jet, Cavitation, Cavitation Cloud, Visualization, Image Analysis

\section{Introduction}

High-speed water jets, where pressurized water or fluid mixture issues from a small nozzle at high speed, have been developed and widely applied to many fields of industry for its peculiar processing property [1] [2] [3]. Among them, high-speed water jet injected into still water is called submerged water jet and it 
has received much attention for its capacity of causing intensive cavitation impact continually with collapsing of cavitation bubbles [4] [5]. For its particular property submerged water jet has been widely applied in various industry fields such as cleaning of complex mechanical products [6], peening of metal materials [7], decomposing and sterilizing of sewage waters [8] [9], and cutting of complex structure materials [10] [11] [12] [13]. Especially in the case of submerged water jet, cutting intensive cavitation is always induced and the processing ability of water jet declines quickly with the standoff distance. For ensuring the effective standoff distance of submerged water jet, Shimizu et al. developed a new type sheathed abrasive nozzle system and its effectiveness has been demonstrated experimentally [14] [15]. But the flow structure and the effect of unsteady cavitation have not been clarified sufficiently [16].

Under this background, many efforts have been made to clarify the flow property of unsteady cavitating water jets. Shimada et al. [17] carried out an investigation on the flow pattern and self-induced vibration of relatively low-speed submerged water jets by dye visualization method. Hutli and Nedeljkovic [18] did an investigation on the frequency of cavitation cloud shedding in submerged cavitating jet by cloud shape analysis. Nishimura et al. [19] decided the similarity of cavitation cloud shedding in cavitating jet induced by an orifice nozzle with a very short shrinking throat. Sato et al. [20] investigated the periodic cavity behavior in a convergent-divergent nozzle by utilizing frame difference method [21] and argued that the re-entrant jet formed by downstream cavitation cloud collapsing is closely related to the cavitation cloud shedding. However, previous works on cavitation jet mainly focused on orifice-type spreading water jet nozzles and usually used a couple of images from one or two cycles to represent the periodic behavior of cavitation cloud discharging. Although cavitation cloud discharging shows an obviously periodicity, they do not behave exactly the same in different cycles. With the above method, only the most dominant frequency component may be detected and it is not sufficient to reveal the complex periodicity induced by different factors. Also, plunger pumps were used in most cases to provide upstream high pressure, and the fluctuation of pump pressure cannot be avoided [22]. Thus cavitation cloud appears differently in high-pressure and low-pressure phases [23]. In addition, in the case of submerged water jet cutting, abrasive nozzles with focusing tube are usually utilized and the structure of cavitating flows in sheathed focusing nozzle should be different from that in spreading nozzle. For the difficulty in observing the interior of intensive cavitation flow, some efforts have been made on the numerical simulation of cavitating water jets [24] [25]. But both modelling of turbulent cavitation flow as well as numerical prediction of cavitation evolution are still suffering from debate and uncertainties [26].

In the present study, the periodic behavior of cavitating water jets issuing from a sheathed pipe nozzle is experimentally investigated by means of high-speed camera and image analysis and the influence of cavitation number on the flow characteristics is examined. All components of dominant frequency of cavitation cloud 
shedding are evaluated by statistical analysis of a series of high-speed camera images and factors affecting the periodic property of cloud shedding are identified. The results demonstrate that the low frequency components of cavitation cloud shedding correspond to the fluctuation of jet injection pressure but the high frequency components should depend upon the flow structure and the property of cavitation clouds consisted of numerous expanded bubbles.

\section{Experimental Apparatus and Experiment Method}

Figure 1 shows the schematic diagram of an open-type test rig for cavitating submerged jet. An open rectangular water tank made of acrylic acid resin is set vertically and a pipe nozzle $(1.0 \mathrm{~mm}$ in diameter) with pipe-like sheath $(3.0 \mathrm{~mm}$ in diameter) is installed at the center of square bottom. For observing its inner flow structure the nozzle is also made of transparent acrylic material. The nozzle is connected to a three-cylinder plunger pump with high-pressure hose. The tank is filled with clear water (tap water settled one night) and the water depth is kept to the level of $750 \mathrm{~mm}$ by using an overflow pipe. Pressurized clear water supplied by the plunger pump issues from the nozzle into the tank and then submerged water jet is formed. The output pressure of the plunger pump is adjustable to its maximum pump pressure of $21.0 \mathrm{MPa}$ according to requirement of experiments. For monitoring of jet injection pressure a high frequency pressure sensor is installed at the pressure pipe just in front of the nozzle and its output is recoded in real time via a data logger. As an index of cavitation performance of the water jet device, cavitation number $\sigma$ is defined as

$$
\sigma=\frac{p_{o}-p_{v}\left(T_{\infty}\right)}{p_{i}-p_{o}}
$$

where $P_{i}$ denotes the jet injection pressure, $p_{o}$ the surrounding static pressure near the nozzle exit and $p_{v}$ the saturated vapor pressure under the reference temperature $T_{\infty}$.

Jet flows issuing from the sheathed nozzle are observed by using a high-speed CMOS camera (Photron: FASTCAM SA-NX2, $1024 \times 1024$ pixels with 12-bit gray level). The observation area is adjusted from the inlet of nozzle throat to the

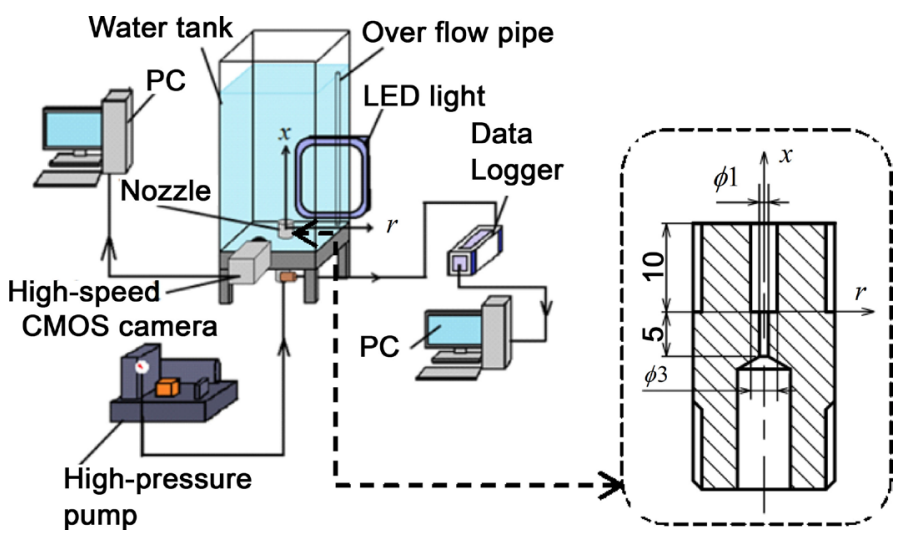

Figure 1. Schematic diagram of experimental device. 
far downstream of sheath exit (5 - 50 d) according to the injection pressure, and the image resolution of camera is set to be $1024 \times 512$ pixels. The shooting frame rate is set to $12,500 \mathrm{fps}$ and the shutter speed is $2.0 \mu \mathrm{m}$. A panel-type LED lamp of $10,500 \mathrm{~lm}$ is used as light source of high-speed imaging to irradiate the jet flows to be observed. Images saved in time sequence are then analyzed by detecting its grey level distribution. For the convenience of describing the jet flow field a cylindrical coordinate system is adopted as shown in Figure 1, where $x$ axis lays in the direction of jet flow and the origin locates at the center of nozzle exit. Experiments were carried out under different cavitation numbers from 0.3 to 0.01 by adjusting the pump output pressure.

\section{Experimental Results and Discussions}

\subsection{Behavior of Cavitation Cloud Shedding}

Figures 2(a)-(d) respectively show, as an example, a series of images in time sequence taken by high speed video camera when $\sigma=0.3,0.1,0.05$ and 0.01 by setting the injection pressure $P_{i}$ to $0.46,1.18,2.23$ and $10.7 \mathrm{MPa}$. Here the surrounding static pressure $p_{o}$ near the nozzle exit is calculated to be $0.107 \mathrm{MPa}$ according to the depth from the water surface to the nozzle exit, and all of the pressures are expressed in absolute ones. The mean velocity at the nozzle exit is estimated to vary from $25 \mathrm{~m} / \mathrm{s}$ to $135 \mathrm{~m} / \mathrm{s}$ and the Reynolds number defined with the nozzle diameter $d$ varies from $2.5 \times 10^{4}$ to $1.3 \times 10^{5}$. The light source was set at the opposite side of the camera and the pictures were taken under penetrating light. So, the area full of water is observed to be bright but the clouds of cavitation bubbles are observed to be dark areas since the cavitation clouds are almost impermeable due to scattering of light at bubble surfaces. As shown in Figure 2 (a), at the moment demonstrated by the first picture from the left cavitation clouds contract almost within the nozzle throat (from $x / d=-5$, the nozzle inlet to $x / d=0$, the nozzle exit), where a long-thin cavity caused by flow separation may be found. With developing of the separation cavity small bubbles shed downstream and cavitation clouds appear near the inlet of sheath $(x / d=0)$ as shown in the second picture. Cavitation clouds formed near the sheath inlet develop gradually and then expand to its maximum as shown in the fourth picture. At this moment most bubbles begin to collapse and cavitation clouds begin to contract as shown in the fifth picture. Sequential cavitation clouds contract to the minimum as shown in the seventh picture and then repeat the same process again as shown by the next pictures. According to the results we understand that cavitation clouds caused in submerged jet expand and contract periodically in the stream direction. The maximum length of cavitation area is evaluated to be $9 d$ approximately. Figure 2(b) shows the appearance of cavitation clouds when $\sigma=$ 0.1 , where we may found that the dark grey area of clouds becomes much heavy. It means that the number density of cavitation bubbles becomes much high and thus most light was irradiated by numerous micro bubbles. The maximum length of cavitation area expands to $16 d$ approximately when $\sigma=0.1$. 
(a)

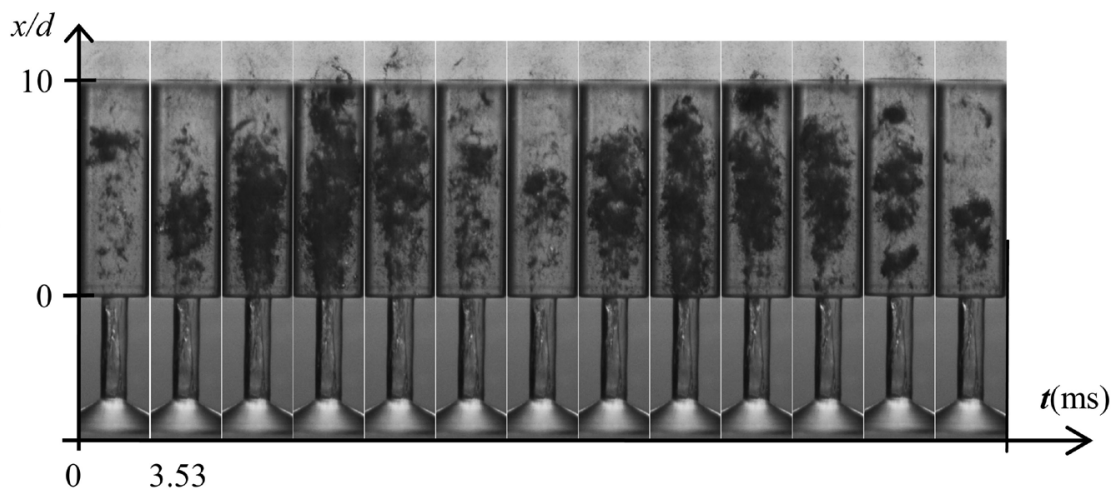

(b)

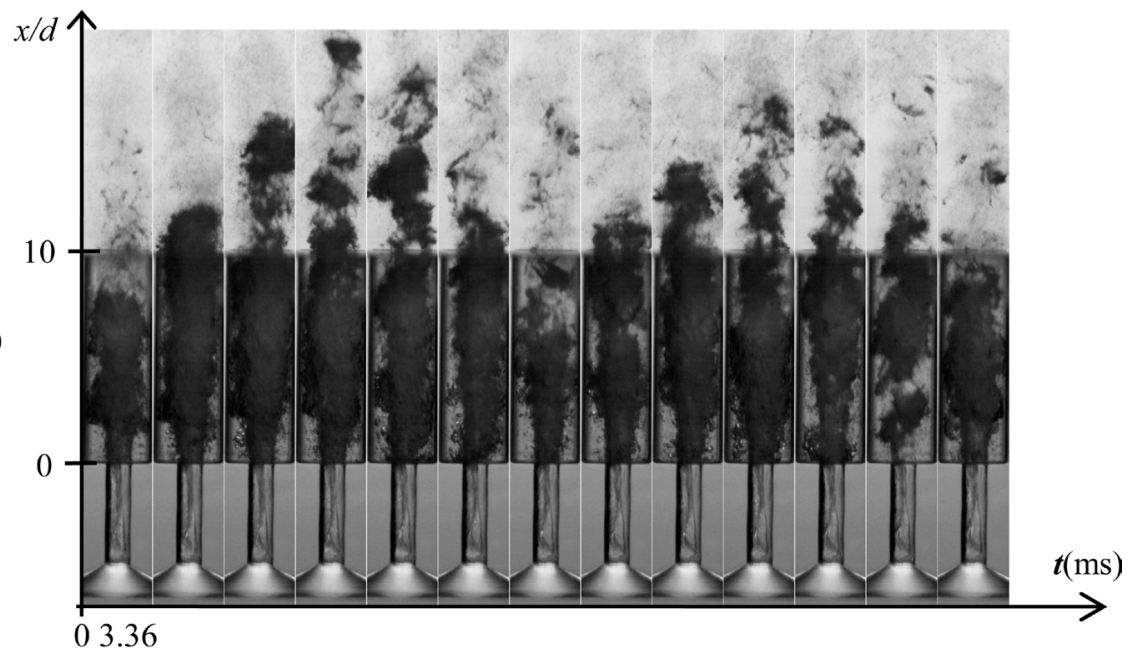

(c)

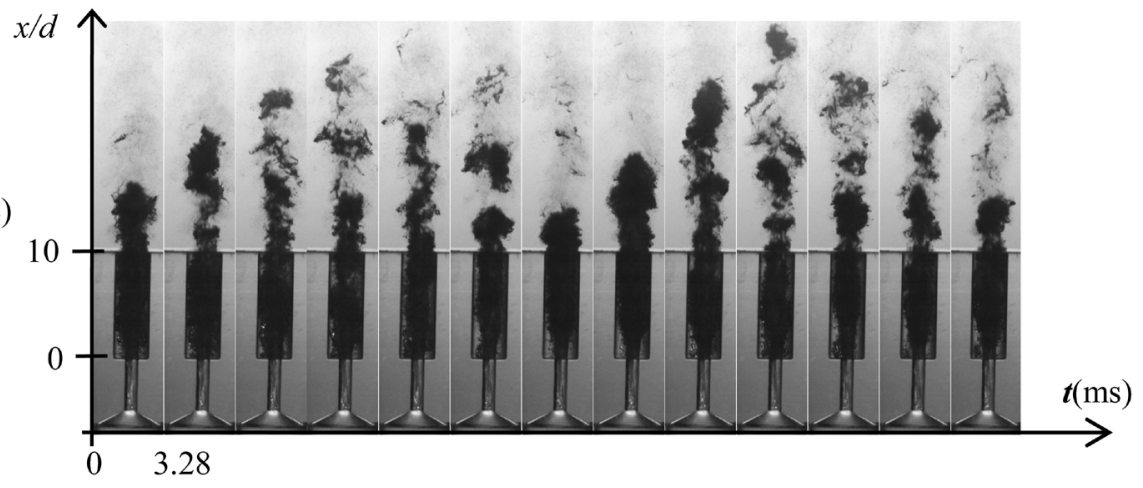

(d)

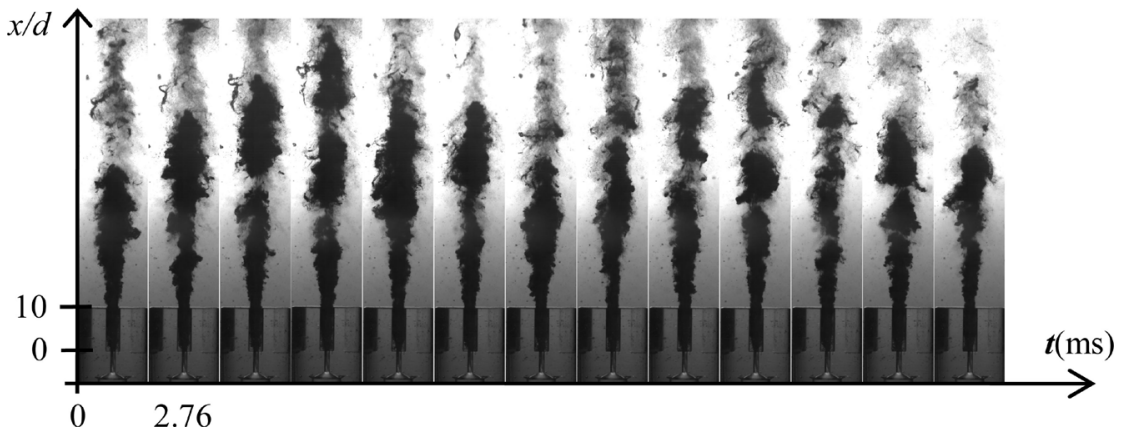

Figure 2. Periodic shedding of cavitation clouds in submerged water jets under different cavitation numbers where (a) $\sigma=0.3\left(P_{i}=0.46 \mathrm{MPa}\right)$; (b) $\sigma=0.1\left(P_{i}=1.18 \mathrm{MPa}\right)$; (c) $\sigma=$ $0.05\left(P_{i}=2.23 \mathrm{MPa}\right) ;(\mathrm{d}) \sigma=0.01\left(P_{i}=10.7 \mathrm{MPa}\right)$. 
Figure 2(c) shows the appearance of cavitation clouds caused in submerged water jet when $\sigma$ is decreased to 0.05 . From the figure we may see that the interior of sheath is almost full of clouds. However, the interior of nozzle throat appears to be light grey where the number density of bubbles should be not so high. Here the maximum length of cavitation area increases to $21 d$ approximately. Figure 2(d) shows the behavior of cavitation cloud shedding when $\sigma=$ 0.01 , where cavitation becomes much intensive and the interiors of nozzle throat and sheath appear to be dark grey that indicates a high number density of bubbles. The maximum length of cavitation area extends to the downstream of $50 \mathrm{~d}$ approximately.

\subsection{Periodic Spectral Characteristics of Cavitation Cloud Shedding}

In order to clarify the periodic characteristics of cavitation cloud shedding, image analysis of high-speed camera photographs was carried out by investigating the temporal variation of grey level. Figure 3(a) shows one of pictures of cavitation cloud taken by high-speed camera. As demonstrated in the figure axial sample images of one pixel width were taken along the central axis and then arranged in time sequence as shown in Figure 3(b), where the average grey level of every sample image is different. Similarly, radial sample images of one pixel width were also taken at $x / d=1.0$ and Figure $3(\mathrm{c})$ shows a series of radial images arranged in time sequence.

The average grey level of every sample image shown in Figure 3(b) and Figure $3(c)$ is then evaluated and the waveform of average grey level variation is investigated. Figure 4(a) demonstrates the temporal variation of the average grey level of the axial images shown in Figure 3(b), which are thought to be the same as the periodic property of cavitation cloud shedding along the axial direction since the grey level of high-speed camera photograph should be closely related

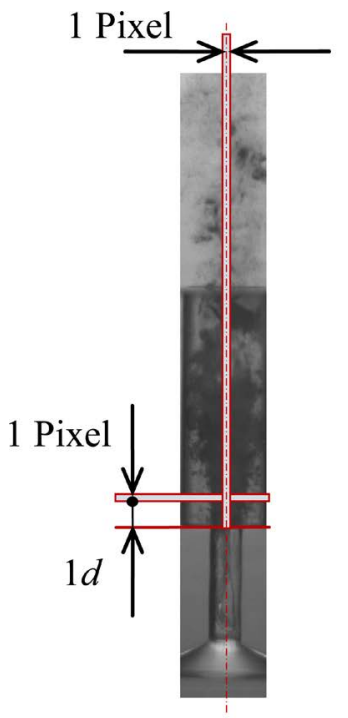

(a) Position of samples

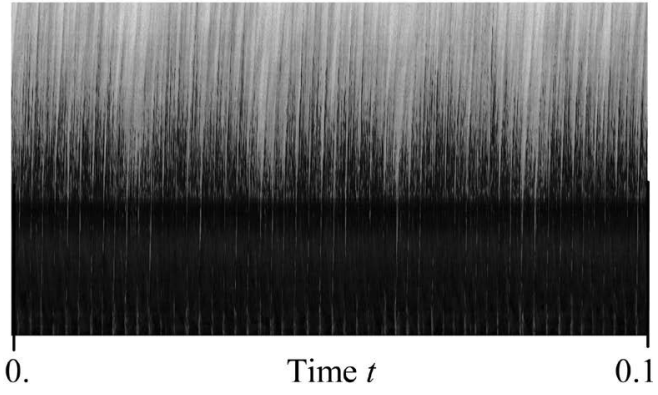

(b) Axial images in time sequence $(r / d=0)$

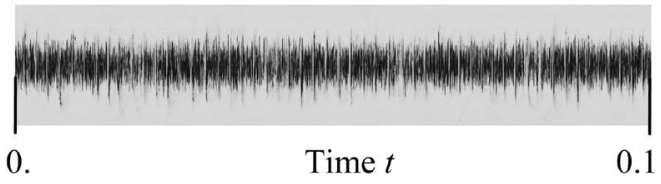

(c) Radial images in time sequence $(x / d=0)$

Figure 3. Sampling positions and one-pixel sample images arranged in time sequence. 
to cavitation events in a local area. Figure 4(b) demonstrates the temporal variation of the average grey level of the radial images shown in Figure 3(c), which should correspond to the oscillation of jet width.

The periodic spectrum of the waveform of the average grey level variation is further investigated by FFT (Fast Fourier Transform) analysis. Figure 5(a) shows the power spectral density (PSD) distribution of the average grey level oscillation in the axial direction, where two dominant frequency components, $f_{1}=$ $48 \mathrm{~Hz}$ and $f_{2}=96 \mathrm{~Hz}$, are demonstrated. That is to say, cavitation clouds stretch and contract mainly at these two frequency components, which are close to the frequency of cylinder reciprocating of the plunger pump adopted. Of course, frequency components of $500 \mathrm{~Hz}, 550 \mathrm{~Hz}$ and $590 \mathrm{~Hz}$ are visible but they are much weaker compared to above dominant frequency components.

Similarly, Figure 5(b) shows the PSD distribution of the average grey level oscillation in the radial direction, where the same dominant frequency components, $f_{1}$ and $f_{2}$ are detected. However, frequency components from $400 \mathrm{~Hz}$ to $2800 \mathrm{~Hz}$ are also visible. The high frequency component of $2800 \mathrm{~Hz}$ is close to the natural frequency of bubble oscillation and the component of $400 \mathrm{~Hz}$ is in the order of vortex shedding [26] [27]. The result demonstrates that the oscillation of jet width is very complex and multiple frequency components have been detected.

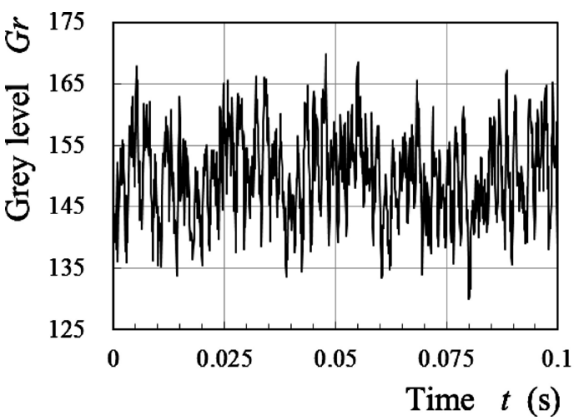

(a)

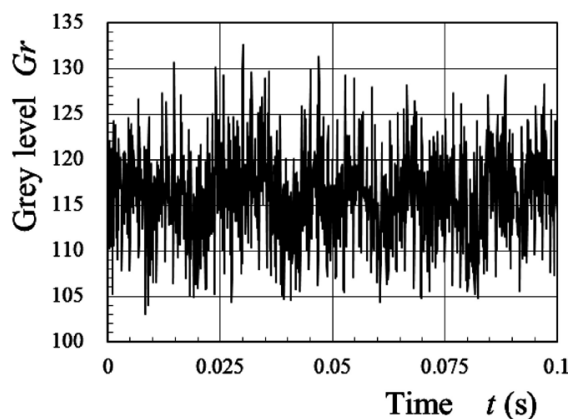

(b)

Figure 4. Waveforms of temporal variation of the average grey level of one-pixel width sample images along: (a) the axial direction at $r / d=0$; (b) the radial direction at $x / d=1$.

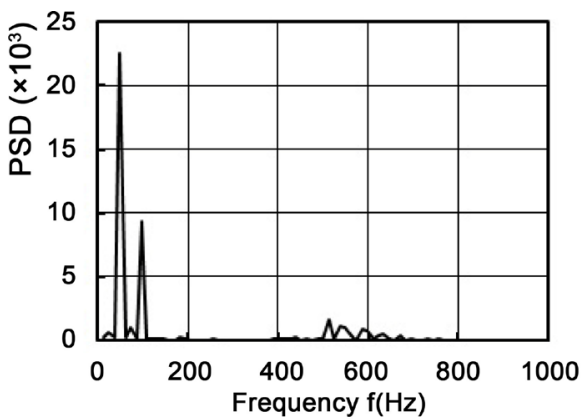

(a)

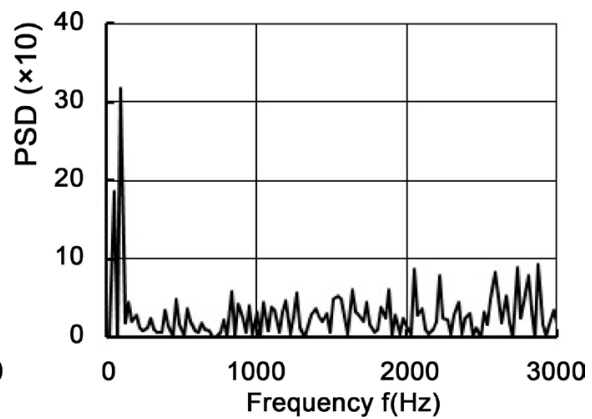

(b)

Figure 5. Dominant frequencies of the average grey level variations $\left(\sigma=0.1, P_{i}=1.18\right.$ MPa): (a) Axial direction; (b) Radial direction. 
Figure 6(a) and Figure 6(b) respectively show the PSD distribution of frequency components of cavitation cloud shedding in the stream direction when $\sigma$ is decreased to 0.05 and 0.01 . According to the results we may understand that the frequency component of $f_{3}=580 \mathrm{~Hz}$ becomes strong while $\sigma$ is decreased to 0.05 . When $\sigma$ is further decreased to 0.01 , much more high frequency components, such as $f_{4}=950, f_{5}=1250, f_{6}=1600, f_{7}=1750$ become prominent and they should be dependent on the collapsing of cavitation clouds consisted of numerous small bubbles.

Figure 7 shows the distribution of dominant frequencies under different cavitation numbers where the symbols $\Delta, \diamond$, *, etc., denote different frequency components and the dashed line denotes the border of frequency spectrum. The figure shows that cavitation cloud shedding becomes visible while $\sigma$ decreases to 0.3 and two main dominant frequencies $f_{1}$ and $f_{2}$ are detected in all experiments under different conditions. With decreasing of cavitation number high frequency components become intensive gradually and multiple frequency components appear simultaneously.

\subsection{Factors Affecting the Shedding of Cavitation Clouds}

In order to specify the factors affecting the shedding of cavitation clouds the temporal variation of jet injection pressure was monitored. Figure 8(a) shows the fluctuation of injection pressure $P_{p}$ where the mean value of $P_{i}$ is evaluated to

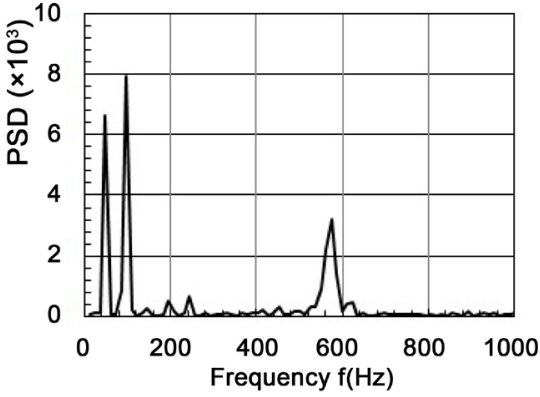

(a)

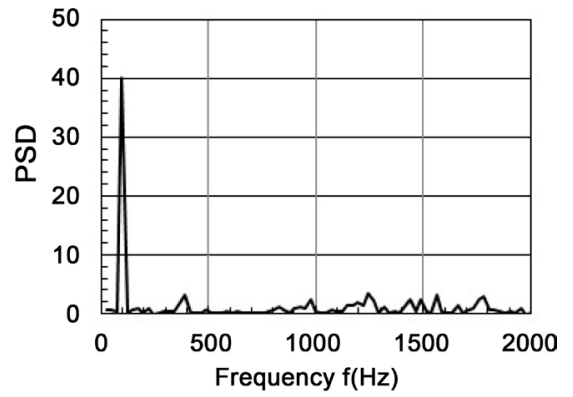

(b)

Figure 6. Dominant frequencies of the average grey level variation in the axial direction: (a) $\sigma=0.05\left(P_{i}=2.23 \mathrm{MPa}\right)$; (b) $\sigma=0.01\left(P_{i}=10.7 \mathrm{MPa}\right)$.

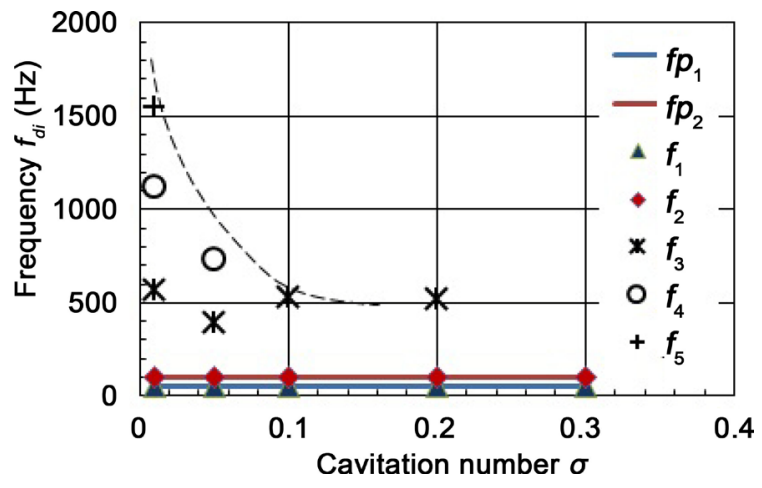

Figure 7. Dominant frequencies of cavitation cloud shedding under different cavitation numbers. 
be 1.0 MPa and the surrounding pressure $p_{o}$ is denoted by dashed line for reference. Figure $8(\mathrm{~b})$ shows the PSD distribution of the pressure fluctuation obtained by FFT analysis. The result reveals that the output pressure of the plunger pump adopted fluctuates at two dominant frequencies of $f_{1}=48$ and $f_{2}=96$, which are coincide with the rotating periodicity of the pump. Comparing Figure 8(b) to Figure 7 we understand that the low frequency components of cavitation cloud shedding correspond to the fluctuation of injection pressure. However, the high frequency components should be closely related to the flow structure and the property of bubble nuclei including in the working liquid.

Concerning the structure of turbulent cavitating bubbly flows, it is still a difficult problem for the complexity of cavitation phenomena. Figure 9 shows a schematic illustration of the structure of cavitating flows issuing from a submerged pipe nozzle, which are conjectured from the high-speed visualization observations [23] [27] [28] [29] and numerical simulations [26] [30]. The core region denotes an area where water jet keeps its power at a high velocity. The wavy line demonstrates an invisible interface between the injected jet stream and ambient water. As shown in the figure, flow separation is expected to occur at the inlet of nozzle throat, which results in the pressure decreases sharply just behind the flow contraction region, where cavitation inception is expected to occur and expanded cavitation bubbles travel downstream along the shear layer around the core region. Travelling bubbles expanded to their maximum limits begin to contract sharply and emit a high impact pressure at the moment of bubble collapsing. Under the effect of impact pressure adjacent bubbles turn to

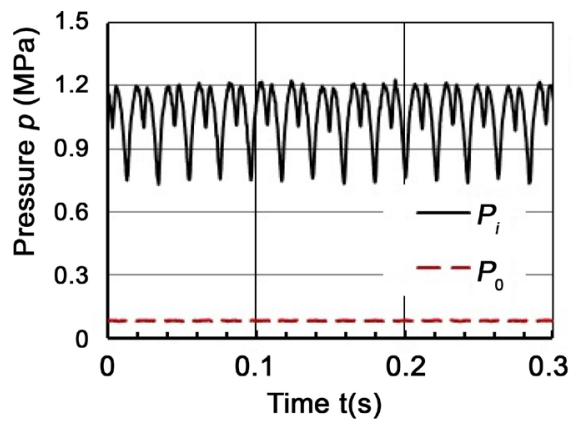

(a)

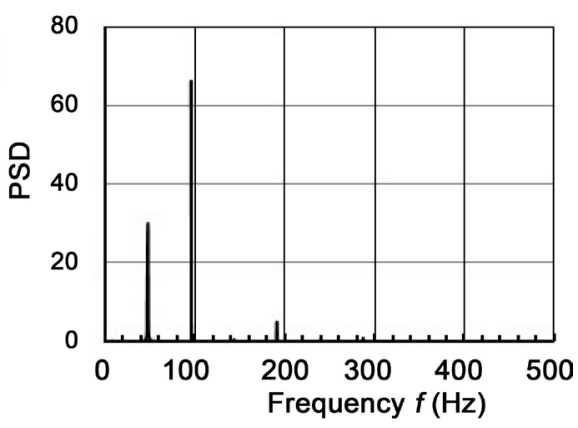

(b)

Figure 8. Pulsation of jet injection pressure supplied with by a three-cylinder plunger pump: (a) Wave form; (b) Dominant frequencies.

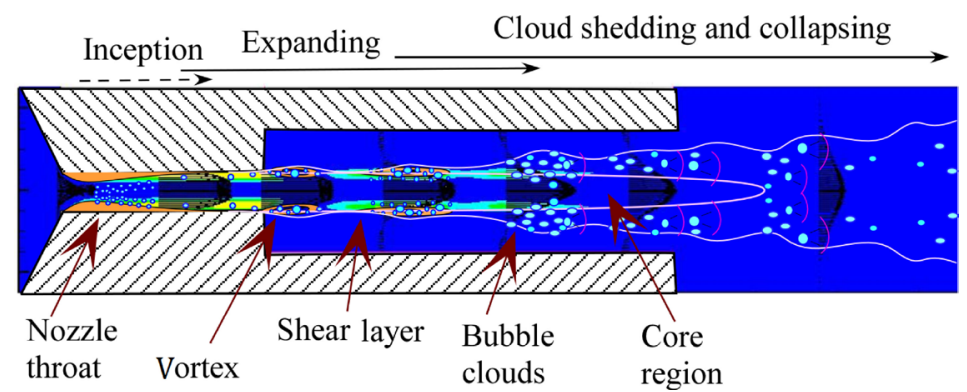

Figure 9. The structure of cavitating jet issuing form submerged pipe nozzle. 
contract accordingly. In this way, cavitation clouds expand and collapse sequentially and it looks like that cavitation clouds shed downstream periodically. The natural oscillation of a mass of bubbles is dependent upon by the number density and the property of bubbles included [24] [31] and the frequency of such a bubble cloud collapsing is almost the same as that one of its natural oscillation. Therefore, the high frequency components of cavitation cloud shedding are dependent on the bubble cloud distribution subjected to the flow structure and the property of bubble nuclei contained in working liquid.

\section{Conclusions}

The behavior of cavitation cloud shedding in submerged water jet issuing from a sheathed pipe nozzle has been investigated by high-speed camera visualization observation. Experiment results demonstrate that:

1) Cavitation occurs and bubble clouds become visible when the cavitation number decreases to the level of 0.5. Corresponding to the fluctuation of surrounding pressure cavitation bubbles expand and contract periodically and then cavitation clouds composed of numerous bubbles shed downstream periodically with collapsing of bubbles.

2) Image analysis reveals that the dominant frequencies of cavitation cloud shedding are closely related to the fluctuation of jet injection pressure, the flow structure of cavitating jet and the property of bubble nuclei contained in working liquid.

3) The periodicity of cavitation cloud shedding corresponds to the fluctuation of jet injection pressure and the low frequency components agree with the frequencies of pressure fluctuation of the plunger pump adopted. The high frequency components are dependent on the flow structure of cavitating jet and the property of bubble nuclei contained in working liquid.

\section{Acknowledgements}

This work was partly supported by JSPS, Grant-in-Aid for Scientific Research (C) (No. 26420124, No. 17K06169). Also, the authors would like to thank Mr. T. Ito et al. for their assistance in experiment works.

\section{References}

[1] Summers, D. A. (1995) Water Jetting Technology. CRC Press, London.

[2] Shimizu, S. and Peng, G. (2009) Water Jetting Technology for LOHAS. International Academic Printing Co. Ltd., Tokyo.

[3] Folkes, J. (2009) Waterjet-An Innovative Tool for Manufacturing. Journal of Materials Processing Technology, 209, 6181-6189. https://doi.org/10.1016/j.jmatprotec.2009.05.025

[4] Michael, M. Wright, B.E., Dropkin, A. and Truscott, T.T. (2013) Cavitation of a Submerged Jet. Experiments in Fluids, 54, 1541-1543. https://doi.org/10.1007/s00348-013-1541-3

[5] Nobel, A.J. and Talmon, A.M. (2012) Measurements of the Stagnation Pressure in 
the Center of a Cavitating Jet. Experiments in Fluids, 52, 403-415. https://doi.org/10.1007/s00348-011-1231-y

[6] Yamaguchi, A. and Shimizu, S. (1987) Erosion Due to Impingement of Cavitating Jet. Journal of Fluids Engineering, 109, 442-447. https://doi.org/10.1115/1.3242686

[7] Soyama, H. (2007) Improvement of Fatigue Strength by Using Cavitating Jets in Air and Water. Journal of Materials Science, 42, 6638-6641. https://doi.org/10.1007/s10853-007-1535-8

[8] Kalumuck, K.M. and Chahine, G.L. (2000) The Use of Cavitating Jets to Oxidize Organic Compounds in Water. Journal of Fluids Engineering, 122, 465-470.

https://doi.org/10.1115/1.1286993

[9] Filho, J.G.D., Assis, M.P. and Genovez, A.I.B. (2015) Bacterial Inactivation in Artificially and Naturally Contaminated Water Using a Cavitating Jet Apparatus. Journal of Hydro-Environment Research, 9, 259-267. https://doi.org/10.1016/j.jher.2015.03.001

[10] Vijay, M. (1992) Comparison of the Performance of High-Speed Abrasive-Entrained, Cavitating and Plain Water Jets for Selective Mining Applications. International Journal of Surface Mining, Reclamation and Environment, 6, 1-9. https://doi.org/10.1080/09208119208944310

[11] Hashish, M. (1989) Pressure Effects in Abrasive-Water Jet (AWJ) Machining. Journal of Engineering Materials and Technology, 111, 221-228. https://doi.org/10.1115/1.3226458

[12] Xu, J. and Summers, D.A. (1994) Experimental Evaluation of the Performance of Fan Jet Systems. Proceeding of 12 th International Symposium of Jet Cutting Technology, Applications and Opportunities, Rouen, 25-27 October 1994, 37-46.

[13] Nanduri, M., Taggart, D.G. and Kim, T.J. (2002) The Effects of System and Geometric Parameters on Abrasive Water Jet Nozzle Wear. International Journal of Machine Tools and Manufacture, 42, 615-623. https://doi.org/10.1016/S0890-6955(01)00147-X

[14] Shimizu, S. and Nishiyama, T. (2004) A Sheathed Nozzle for Abrasive Water Suspension Jets in Submerged Environments. Proceeding of 17 th International Conference on Water Jetting, BHR Group Ltd., 197-204.

[15] Shimizu, S., Sakuma, M., Hitomi, K. and Peng, G. (2010) Submerged Cutting by Abrasive Suspension Jet Issuing from Sheathed Nozzle with Ventilation. Proceeding of 20 th International Conference on Water Jetting, BHR Group Ltd., 435-441.

[16] Shimizu, S., et al. (2015) Submerged Cutting Characteristics of Abrasive Suspension Jet. Transactions of the JSME, 81, 15-00361. (In Japanese) https://doi.org/10.1299/transjsme.15-00361

[17] Shimada, N., Hibara, H., Ishibashi, Y., Sumida, M. and Sudo, K. (2004) Analysis of Submerged Water Jets by Visualization Method. Journal of Visualization, 7, 281-289. https://doi.org/10.1007/BF03181532

[18] Hutli, E.A.F. and Nedeljkovic, M.S. (2008) Frequency in Shedding/Discharging Cavitation Clouds Determined by Visualization of a Submerged Cavitating Jet. Journal of Fluids Engineering, 130, Article ID: 021304.

[19] Nishimura, S., Takakuwa, O. and Soyama, S. (2012) Similarity Law on Shedding Frequency of Cavitation Cloud Induced by a Cavitating Jet. Journal of Fluid Science and Technology, 7, 405-420. https://doi.org/10.1299/jfst.7.405

[20] Sato, K., Taguchi, Y. and Hayashi, S. (2013) High Speed Observation of Periodic Cavity Behavior in a Convergent-Divergent Nozzle for Cavitating Water Jet. Journal 
of Flow Control, Measurement \& Visualization, 1, 102-107. https://doi.org/10.4236/jfcmv.2013.13013

[21] Hayashi, S. and Sato, K. (2014) Unsteady Behavior of Cavitating Waterjet in an Axisymmetric Convergent-Divergent Nozzle: High Speed Observation and Image Analysis Based on Frame Difference Method. Journal of Flow Control, Measurement \& Visualization, 2, 94-104. https://doi.org/10.4236/jfcmv.2014.23011

[22] Wright, M.M., Epps, B., Dropkin, A. and Truscott, T.T. (2013) Cavitation of a Submerged Jet. Experiments in Fluids, 54, 1-21. https://doi.org/10.1007/s00348-013-1541-3

[23] Peng, G., Masuda, K. and Shimizu, S. (2013) Characteristics of Cavitating Water Jet Issuing from a Sheathed Orifice Nozzle. Proceedings of FLUCOME, No. OS7-01-3, 1-8.

[24] Peng, G. and Shimizu, S. (2013) Progress in Numerical Simulation of Cavitating Water Jets. Journal of Hydrodynamics, 25, 502-509. https://doi.org/10.1016/S1001-6058(11)60389-3

[25] Peng, G., Tryggvason, G. and Shimizu, S. (2015) Two-Dimensional Direct Numerical Simulation of Bubble Cloud Cavitation by Front-Tracking Method. IOP Conference Series: Materials Science and Engineering, 72, Article ID: 012001. http://iopscience.iop.org/1757-899X/72/1/012001/

[26] Wang, Y., Qiu, L. and Reitz, R.D. (2014) Simulating Cavitating Liquid Jets using a Compressible and Equilibrium Two-Phase Flow Solver. International Journal of Multiphase Flow, 63, 52-67. https://doi.org/10.1016/j.ijmultiphaseflow.2014.03.006

[27] Zelenak, M., Foldyna, J., Scucka, J, Hloch, S. and Riha, Z. (2015) Visualisation and Measurement of High-Speed Pulsating and Continuous Water Jets. Measurement, 72, 1-8. https://doi.org/10.1016/j.measurement.2015.04.022

[28] Nanduri, M., Taggart, D.G. and Kim, T.J. (1996) High-Speed Observation of Ultrahigh-Speed Submerged Water Jets. Experimental Thermal and Fluid Science, 12, 411-416. https://doi.org/10.1016/0894-1777(95)00124-7

[29] Watanabe, R., Kikuchi, T., Yamagata, T. and Fujisawa, N. (2015) Shadowgraph Imaging of Cavitating Jet. Journal of Flow Control, Measurement \& Visualization, 3, 106-110. https://doi.org/10.4236/jfcmv.2015.33010

[30] Peng, G., Yang, C., Oguma, Y. and Shimizu, S. (2016) Numerical Analysis of Cavitation Cloud Shedding in a Submerged Water Jet. Journal of Hydrodynamics, 28, 986-993. https://doi.org/10.1016/S1001-6058(16)60700-X

[31] Brennen, C.E. (1995) Cavitation and Bubble Dynamics. Oxford University Press, New York. 